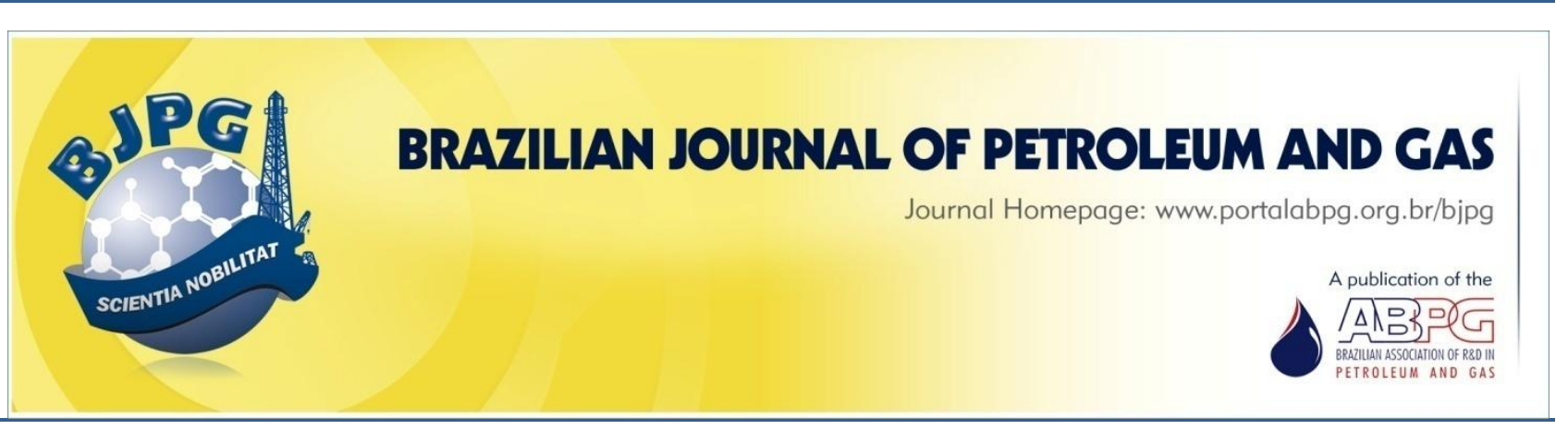

\title{
EVALUATION OF THE STRESS STATE AROUND BOREHOLES USING WELL LOG DATA: A CASE STUDY IN THE SERGIPE-ALAGOAS BASIN, BRAZIL
}

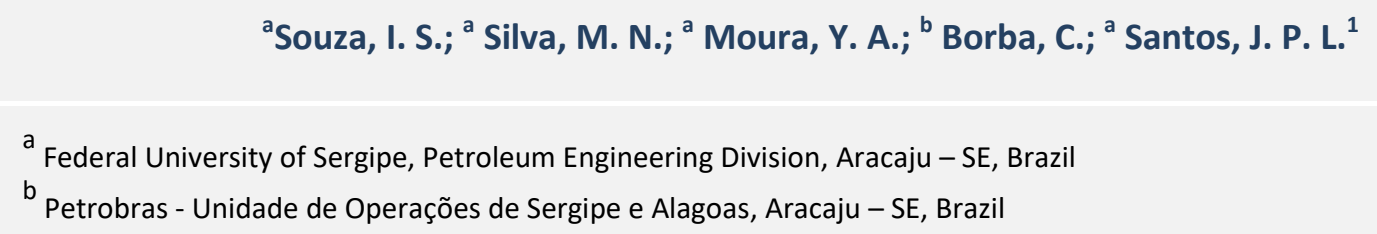

\begin{abstract}
The oil industry has been investing heavily in studies focused on secondary recovery methods. In this context, water injection represents one of the leading methods used to obtain an increase in recovery factor. Studies to determine geomechanical parameters of rocks through the application of Zoback's equations (Zoback, 2007) using only well logging data are sparse. This work studies the variations of the in-situ stress state around the injector well in a reservoir through the application Zoback's equations aiming to identify the maximum injection pressure limit to prevent rock fracturing. For the study, the insitu stresses of the rock were determined using well log data acquired from drillings in a basing located in the Brazilian northeast. The study also considers the Mohr-Coulomb rupture criterion in the determination of the safe region. The results obtained by Mohr-Coulomb rupture criterion were validated with the absorption pressure values obtained with direct data of Leak Off Test (LOT) done in the wells. From the results obtained, it was possible to verify that the calculated values overestimated rupture pressures presenting an average relative error of $7.87 \%$. Furthermore, the stress regime obtained for the Sergipe-Alagoas basin is agreement with other studies found in the literature.
\end{abstract}

\section{KEYWORDS}

recovery methods; water injection; fracture pressure; rupture criterion; mohr-coulomb; maximum injection pressure

\footnotetext{
${ }^{1}$ To whom all correspondence should be addressed.

Address: Federal University of Sergipe, Petroleum Engineering Division, Av. Marechal Rondon, S/N - Jardim Rosa Elze, São Cristóvão, SE, Brazil.

ZIP Code: 49100-000 | Phone number: +55 (79) 31946593 | e-mail: itson ss@hotmail.com; maripetufs@gmail.com; yamrkb@mst.edu; iplobo@ufs.br; clborba@uol.com.br doi:10.5419/bjpg2020-0008
} 


\section{INTRODUCTION}

Secondary recovery is a method used to supplement the primary energy of the reservoir that was lost during the oil production. This method consists of fluid injection, which pushes the oil and occupies the empty spaces left in the porous media, serving both to accelerate production and to re-pressurize the reservoir, thus, increasing its recovery factor (Rosa et al., 2011). Among the methods available, the water injection represents the most used secondary recovery method used in oil industry for maintaining reservoir pressure and achieving voidage replacement due to its low cost of operation, its facility to operate, and its availability from nearby rivers, streams, oceans, or from wells drilled into less deep waters (Amadi et al., 2017).

Injection and/or fluid production in a reservoir modifies saturation and pressure within the porous media and changes the effective stresses around the wellbore (Hussein \& Heiland, 2018). This affects the stress states of rocks, which may result in, among other factors, pore collapse, rock fracture, sand production, surface subsidence, reactivation of geological faults, exudation, and, in more critical situations, blowouts. Therefore, controlling the water injection pressure to prevent water breakthrough and floods along natural fractures is an effective measure for improving the waterflooding development effect (Lyu et al., 2018). It is also very important that the integrity of the cap rock be preserved to avoid environmental problems such as exudation or contamination of aquifers. Thus, the precise estimation of reservoir geomechanical parameters can lessen that risk and provide benefits all the way through oil and gas field's lifespan (Hussain \& Ahmed, 2018).

In projects such as hydraulic fracturing and enhanced-oil-recovery injection, knowing the fracture gradient of the injection zone is necessary (Mollakhorshidi \& Arabjamaloei, 2012). The current practices of injecting water in many natural fracture reservoirs show that currently operators generally use the formation-parting pressure as a guide for injection pressures, such as using the formation parting pressure as the maximum threshold value of the water injection pressure (Cao et al., 2012). Therefore, a correct estimate of the fracture gradient is extremely important for the success of the secondary recovery method.
Typically, direct methods such as formation pressure integrity test (FIT) and the formation leakoff test (LOT) are performed in drilling operations to evaluate cement placement, determine the casing setting depth, test the resistance of tensile failures of a casing shoe, and estimate formation fracture gradient (Postler, 1997). According to Mollakhorshidi and Arabjamaloei (2012), many researchers have used well logging data to develop empirical correlations. Matthews and Kelly (1967) used the matrix-stress-ratio concept to predict fracture pressure in normally pressured formations along the U.S. Gulf Coast. To improve Matthews and Kelly's approach, Pennebaker (1968) developed a similar correlation, by accounting for variable Gulf coast overburden. One of the popular prediction techniques is Eaton's correlation (Eaton, 1969), based on offshore Louisiana data in moderate water depths. McPherson and Berry (1972) developed a correlation between elastic modulus for a compressional wave and formation fracture pressure using measurements of interval transit time by means of a sonic log and bulk density by means of a density log to calculate the elastic modulus and fracture pressure gradient. Anderson et al. (1973) presented a particular method for the Gulf coast area that uses open hole log-porosity measurements and calibrated leak off test data to estimate the fracture gradient in sandstone. Daines (1982) offered a procedure for estimating fracture gradients in variable lithology and in those regions in which little information is available. Holbrook et al. (1993) used porosity to develop an empirical model for fracture pressure gradient, finding that results were in agreement with lower-bound fracture pressures evidenced in the North Sea and other areas.

The Mohr-Coulomb failure criterion is often applied to the description of intact rock failure (Manshad et al., 2014; Hackston \& Rutter, 2016), and can be used to determine the stress state that leads to rock rupture (Zoback, 2007). The MohrCoulomb criterion is relatively simple, therefore, being one of the most used in the oil industry. Moreover, this criterion of rupture can be applied using well logging data, representing a low-cost alternative methodology when compared to other methods applied during drilling.

Approaches of theoretical studies to determine geomechanical parameters of rocks, as well as fracture stresses, through the application of 
Zoback's equations (Zoback, 2007), using only well logging data is seldom found in the literature. The main objective of this study is to determine fracture stresses of the rock applying the equations approached by Zoback (2007), using only well logging data from a basin located in the Brazilian northeast area, and the Mohr-Coulomb rupture criterion for indicating the maximum limit of the injection pressure so that the fracture of the reservoir cap rock does not occur. To compare and validate the results predicted by the MohrCoulomb rupture criterion, we used LOT data from the wells.

\section{IN-SITU STRESSES}

The estimation of geopressure is one of the most important steps for the establishment of an engineering design of drilling operations and well design (Santos et al., 2018). In the process, existing subsurface formations are subjected to a compressive stress state. This state of stress is called in-situ stress, being formed by three mutually orthogonal stresses, as shown in Figure 1. A vertical stress (Sv), given by the weight of the overlying rock layers, assumed by the overload strain (overburden), and two horizontal stresses (minimum horizontal stress, $S_{\text {hmin, }}$ and maximum stress, $S_{H \max }$ ), which are responses to the lateral deformations caused by the weight of the overlapping layers and the tectonic stresses acting in the area.

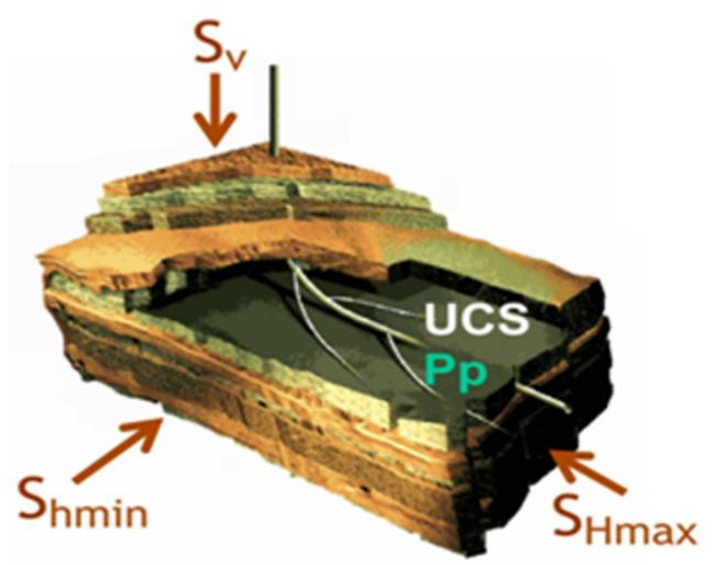

Figure 1. In-situ stresses on a rock element (Zoback, 2007).
Where, UCS is the unconfined compressive strength of the rock and it is obtained through the uniaxial compression test or by mathematical correlations applying the data of the geophysical profiles, as given by Equation (18) (Lal, 1999; Jesus et al., 2019).

The overload stress on a rock element in the subsurface, at a given depth, is composed by the cumulative weight of all formations and fluids contained on the pores over a point in this depth (Doyle et al., 2003).

According to Fjaer et al. (2008), the overburden stress $\left(\sigma_{o v}\right)$ can be obtained by Equation (1):

$G_{o v}=\frac{\int_{0}^{z} \rho_{b} g d z}{0.1704 D}$

Where, $G_{o v}$ is the overload gradient (Ib/gal) calculated by Fjaer relating the density of the superposed layers $(\rho b)\left(g / \mathrm{cm}^{3}\right)$, the gravitational constant $(\mathrm{g})$, the depth of the increments $(\mathrm{dz})$, and $y$ is the depth of the layer (D).

The horizontal in-situ stresses are derived from a phenomenon called bilateral restriction, coming from a problem found in the theory of linear elasticity. The method assumes that, because there is no lateral deformation (Poisson effect), in response to vertical efforts caused by the confined space, the horizontal stresses increase with increasing vertical stresses. There are several models for determining minimum horizontal stress, one of them being shown in the Equations (2) until (4), respectively, respectively (Zoback, 2007).

$\sigma_{h}=\sigma_{f}=G_{p}+K\left(G_{o v}-G_{p}\right)$

According to Molaghab et al. (2017), hydraulic fracturing test, leak-off test (LOT), and measurement of pressure while drilling (PWD) are three common methods for the least principal stress measurement in deep wells. The minimum horizontal stress is determined by considering that the same equal to the rock fracture gradient $(\sigma \mathrm{h}=$ Gf) and, for determining the rock matrix coefficient (K), measured values of the LOT should be available, and Equations ( 3 ) and (4) can be used. In the case of no minimum horizontal stress data to be available, the industry uses, as proxy, the absorption pressure obtained in the LOT. Equation (3) represents the effective stresses and considers 
the effects of pore pressure on the rock (Rocha and De Azevedo, 2009).

$K=\frac{L O T-G_{P}}{G_{o v}-G_{P}}$

$K=a \ln (\Delta Z)+b$

Where, $\sigma_{h}$ is the minimum horizontal stress (psi), $G_{p}$ is the pore gradient (lb/gal), $K$ is the rock matrix coefficient, $a$ and $b$ are constants, and $\Delta Z$ is sediment thickness $(\mathrm{m})$.

According to Zoback (2007), the maximum horizontal stress is obtained by Equation (5):

$\sigma_{H}=3 \sigma_{h}-2 G_{p}$

Where, $\sigma_{H}$ is the maximum horizontal stress.

\subsection{Stress around the well}

At the moment a well starts the injection process, displacing the fluids within the rock, there is a change in the existing stress state. Initially in the well wall and, then, in the radial direction. The stresses around the well are integral parts of the in-situ stresses. A large concentration of tensions acting around the well can lead to rock rupture. Therefore, the stresses generated around the well are functions of the hydrostatic pressure of the injected fluid. Basically, a stability analysis of the rock consists of determining the stress to be used during the injection to avoid rock rupture (Rocha \& De Azevedo, 2009).

According to Azevedo (2011), to obtain the equations governing the stress state around the well, shown in Figure 2, some hypotheses have to be adopted:

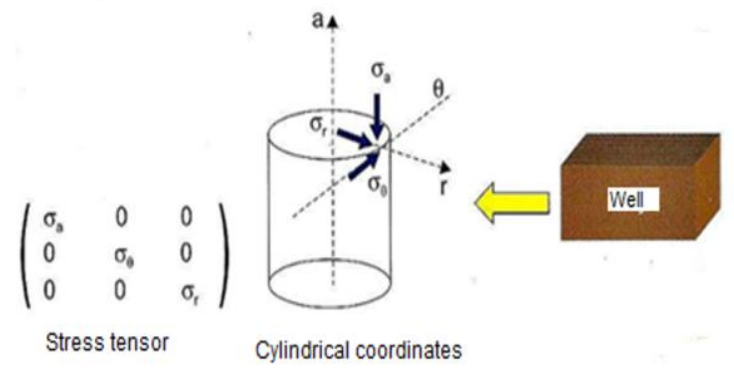

Figure 2. Representation of a state of tensions acting around the well in cylindrical coordinates (adapted from Rocha \& De Azevedo, 2009).
- Rock material is considered as a continuous medium, elastic, linear, and homogeneous;

- The cross section of the well is considered circular;

- One of the principal stresses in the Earth's crust acts in the vertical direction.

Manshad et al. (2014) presents the equations of the effective principal stresses around a well submitted to an anisotropic stress state as showed in the Equations (6) by (9):

$\sigma_{r}^{\prime}=P_{w}-P_{p}$

$\sigma_{\theta}^{\prime}=\sigma_{H}+\sigma_{h}-2\left(\sigma_{H}-\sigma_{h}\right) \cos (2 \theta)-$

$-P_{w}-3 P_{p}-\sigma^{\Delta t}$

$\sigma_{a}^{\prime}=\sigma_{o v}-2 v\left(\sigma_{H}-\sigma_{h}\right) \cos (2 \theta)-$

$-P_{p}-\sigma^{\Delta t}$

$\tau_{r \theta}=\tau_{r a}=\tau_{\theta a}=0$

Where, $\sigma_{r}^{\prime}, \sigma_{\vartheta}^{\prime}$ and $\sigma_{a}^{\prime}$ are the normal effective principal stresses in the radial, tangential, axial directions, and $\tau_{r \vartheta}, \tau_{\vartheta a}$, and $\tau_{r a}$ are the shear stresses relative, respectively, to the plane parallel to the well, to the plane which contains the axis of the well, and the plane normal to the axis of the well; $P_{w}$ is the internal pressure of the well; $\vartheta$ is the angle measured counterclockwise, in the $x-y$ plane, from the $x$-direction.

Since the angle $\theta$, measured in relation to the maximum horizontal stress, is equal to 0 or $\pi$ for the equations to represent the principal stress, we have the following simplification:

$$
\begin{aligned}
& \sigma_{\theta}^{\prime}=3 \sigma_{h}-\sigma_{H}-P_{w}-3 P_{p}-\sigma^{\Delta t} \\
& \sigma_{a}^{\prime}=\sigma_{o v}^{\prime}-2 v\left(\sigma_{H}-\sigma_{h}\right)-P_{p}-\sigma^{\Delta t} \sigma_{a}^{\prime}= \\
& =\sigma_{o v}^{\prime}-2 v
\end{aligned}
$$

Where, $\sigma_{r}$ is the radial stress and it equals the hydrostatic pressure of the fluid acting inside the well walls, exerting the same tension in all directions inside the well, radially; $\sigma_{\vartheta}$ is the tangential stress, it is the function of the horizontal stresses and it acts tangentially to the axis of the well; $\sigma_{a}$ is the axial stress, it is a function of the overload stress and acts parallel to the well. 


\subsection{Mohr-Coulomb rupture criterion}

The rupture criteria are relations between the stresses corresponding to the state of rupture of a given material. In the case of rocks, it is common to associate the stress state, which will occur to the rupture of the rock, corresponding to the stressstrain curve.

The shear-slip analytical models are developed using principal effective stresses, stress plane orientations, and fluid pressure acting within the porous medium. These are the most frequent choices for a first geomechanical analysis, since the analytical models may underestimate or overestimate the maximum injection pressure due to the simplifications and approximations adopted in geometry and initial stresses (Rutqvist et al., 2006).

In rock mechanics, material breakdown analysis usually is a comparison between the internal stresses with the strength of the material. If the stresses do not exceed the tensile, compression, shear, or impact strength limit, then, the material remains intact and the injection operation is performed in a safe state (Aadnøy, 2014). A more general and frequently used criterion is the MohrCoulomb criterion, which assumes that shear stress is a linear function of the effective stress applied on the rocks. This criterion, because it is relatively simple, disregards the intermediate principal stress $\sigma 2$ and consists of a rupture envelope in the cartesian plane, where the circle represents the state of critical stress acting on the rock, that is, the state of tension that will lead to fracture of the rock by shearing, resulting from compression

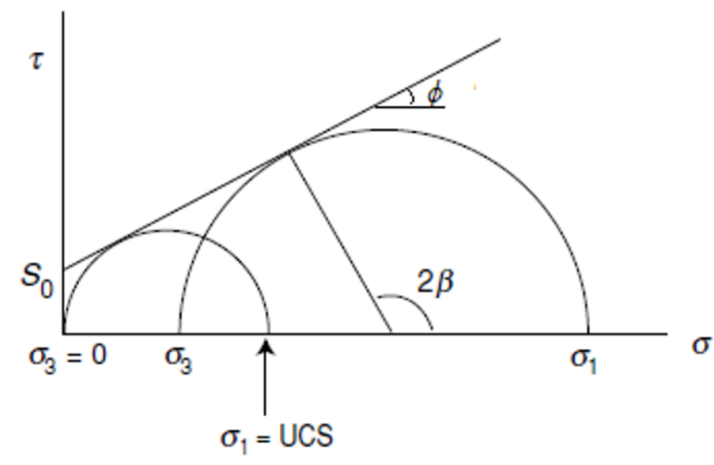

Figure 3. Schematic for defining the Mohr-Coulomb criterion (adapted from Zoback, 2007). efforts applied on the rock during a triaxial test. Therefore, the Mohr-Coulomb criterion is one of the most used rupture criteria in the oil industry (Fjaer et al., 2008).

The Mohr-Coulomb envelope (or rupture envelope) is composed of two regions, as one can see in Figure 3. One region is considered stabilized, below the envelope, and another, above the tangent line, is considered a non-stabilized or rupture region (Rocha \& De Azevedo, 2009).

In the plane $\tau x \sigma$ the instability occurs when the shear stress, $\tau$, reaches the limit value expressed in terms of the effective normal stress, determined by Equation (12) (Almisned et al., 2017).

$\tau=S_{o}+\mu \sigma$

Where, $S_{0}$ corresponds to the cohesion of the rock and $\mu$ it is the coefficient of internal friction.

The cohesion of the rock is determined by Equation (13), and it is the point where the envelope intercepts the $y$-axis (shear stress). It can be determined when the normal stress $(\sigma), x$-axis, is zero. The angle friction, angle $\varphi$, is related to the coefficient of internal friction by Equation (14) and it can be approximated by Equations (15) and (16) for clayey rocks and sandstones, respectively, (Lal, 1999; Jesus et al., 2019).

$$
\begin{aligned}
& S_{o}=\frac{U C S}{2\left(\sqrt{\mu^{2}+1}+\mu\right)} \\
& \mu=\tan (\phi)=2 \beta \\
& \phi=\sin ^{-1}\left(\frac{V_{p}-1000}{V_{p}+1000}\right) \\
& \phi=57.8-105 \varphi
\end{aligned}
$$

Where, $\Delta t$ is transit time of the compressional wave.

Thus, it is possible to define the Mohr circles as a relation between shear and normal stresses at the point of contact, in terms of the principal stresses $\sigma_{1}$ and $\sigma_{3}, 2 \beta$ is the contact angle between the Mohr circle and the rupture envelope, and $\emptyset$ is the porosity of the rock (Rocha \& De Azevedo, 2009), according to Equations (19) and (20). 
$V_{p}=\frac{304800}{\Delta t}$

$U C S=1.35\left(\frac{304.8}{\Delta t}\right)^{2.6}$

Where, $\Delta t$ is transit time of the compressional wave.

Thus, it is possible to define the Mohr circles as a relation between shear and normal stresses at the point of contact, in terms of the principal stresses $\sigma_{1}$ and $\sigma_{3}, 2 \beta$ is the contact angle between the Mohr circle and the rupture envelope, and $\emptyset$ is the porosity of the rock (Rocha \& De Azevedo, 2009), according to Equations (19) and (20).

$\tau=\frac{1}{2}\left(\sigma_{1}-\sigma_{3}\right) \sin (2 \beta)$

$\sigma=\frac{1}{2}\left(\sigma_{1}+\sigma_{3}\right)+\frac{1}{2}\left(\sigma_{1}-\sigma_{3}\right) \cos (2 \beta)$

From Figure 3 it is possible to verify that the increase in fluid pressure on the rock can induce instability by compression for it increases the radius of the Mohr circle, which can lead to even exceed the limit of rupture (rupture envelope). In this context, the injected fluid with the use of recovery methods can promote an imbalance in the stress state acting on the reservoir, especially the tangential stress and, thus, increasing the magnitude of the shear stress, and possibly leading to rock rupture. Once the maximum and minimum stresses are known, the Mohr circle can be simply constructed, and the maximum shear stress can be defined by Equation (21), which defines the maximum pressure in which the fluid can be injected without causing rock rupture:

$\tau_{\text {máx }}=$ Radius $=\left(\frac{\sigma_{1}-\sigma_{3}}{2}\right)$

Figure 3 shows that the larger the stress differential between $\sigma 1$ and $\sigma 3$ is, the greater the radius of the circle will be Eq. (21), being directly proportional to the maximum shear stress.

\section{METHODS AND DATA}

The methodology applied in the present work was based on the results of the work of Santos et al. (2015), Santos Jr (2015), and Silva et al. (2018).
Table 1. Repeat Formation Test data (Santos et al., 2015).

\begin{tabular}{cccc}
\hline $\begin{array}{l}\text { Depth } \\
(\mathbf{m})\end{array}$ & $\begin{array}{c}\text { Gp } \\
(\mathbf{l b} / \text { gal })\end{array}$ & $\begin{array}{c}\text { Depth } \\
(\mathbf{m})\end{array}$ & $\begin{array}{c}\text { Gp } \\
(\mathbf{l b} / \text { gal })\end{array}$ \\
\hline 953.2 & 8.35 & $1,923.2$ & 7.00 \\
993.2 & 8.34 & $1,925.8$ & 6.99 \\
$1,023.9$ & 8.35 & $1,939.6$ & 6.71 \\
$1,831.1$ & 8.18 & $1,943.6$ & 6.68 \\
$1,844.7$ & 8.45 & $1,974.7$ & 5.41 \\
$1,847.4$ & 8.34 & $1,975.3$ & 5.45 \\
$1,855.3$ & 7.86 & $2,012.4$ & 8.03 \\
$1,857.9$ & 7.69 & $2,020.1$ & 6.46 \\
$1,871.9$ & 5.56 & $2,121.9$ & 6.14 \\
$1,882.4$ & 6.53 & & \\
\hline
\end{tabular}

Table 2. Transit Time $(\Delta t)$ and Leak off Test (LOT) data (Santos Jr, 2015).

\begin{tabular}{ccc}
\hline Depth $(\mathrm{m})$ & $\boldsymbol{\Delta t}(\boldsymbol{\mu s} / \mathrm{ft})$ & LOT $(\mathrm{lb} /$ gal) \\
\hline 347 & 111.08 & 15.40 \\
487 & 99.78 & 17.20 \\
977 & 93.81 & 19.80 \\
997 & 79.84 & 16.55 \\
1,097 & 88.36 & 15.17 \\
1,485 & 79.66 & 15.30 \\
1,495 & 76.89 & 15.97 \\
2,235 & 64.99 & 18.10 \\
\hline
\end{tabular}

It was obtained from two well logs from the Sergipe/Alagoas Basin, known as well $X$ and well $Y$ that were combined and considered as one well.

Data from the profiles were processed and organized into a spreadsheet using Microsoft Office Excel software, version 2010. The wells provide depth, density, and sonic profiles measured between depths 267 to 2,395 meters, in addition to Repeat Formation Test (RFT), and Leak off test (LOT) data presented in Tables 1, 2 and Figure 4, which served as the basis for calculation and calibration of the gradients of in-situ stresses.

The RFT pore pressure values below $8.3 \mathrm{ppg}$ should be disregarded because they are nonoriginal pressures obtained from depleted reservoirs.

From these results, one can calculate the in-situ stresses represented by equations (1), (2), and (5). The overload stress was obtained through the data of the density logs. The minimum horizontal stress with the point values of the rock matrix coefficient 
a)

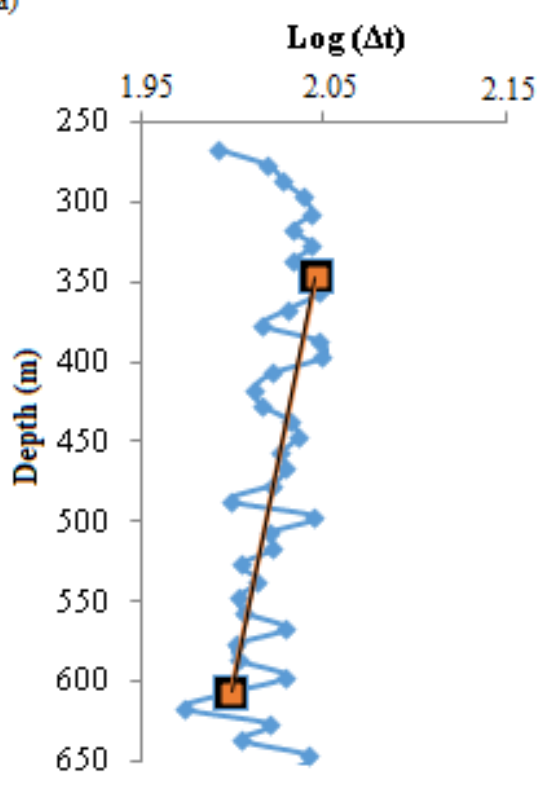

b)

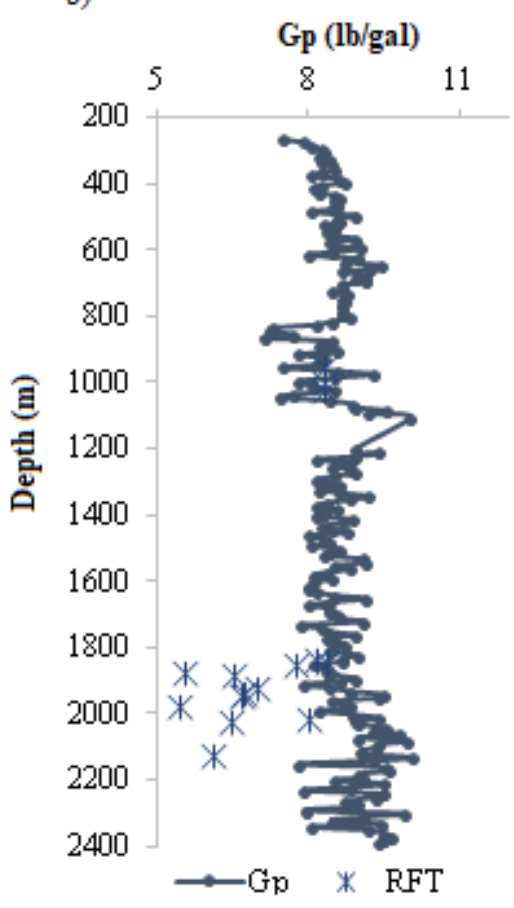

Figure 4. a) Normal compaction trend curve for $X$ and $Y$ wells, and $b$ ) Pore pressure gradient of the $X$ and $Y$ wells (adapted from Silva et al., 2018).

(K) estimated by Equation (3), which relates the values of the absorption pressure obtained by the LOT data, is shown in Table 2. To extrapolate the values of the stress coefficient of the rock matrix (K) for the entire area of study, a K curve versus a sediment thickness was adjusted to the estimate points calculated previously from Equation (3). The logarithmic equation of the line, represented by Equation (4), represents the value of $\mathrm{K}$ for the entire study area. And, finally, the maximum horizontal stress was determined from Equation (5).

Then, the stresses around the wells were determined by applying Equations (6), (10), and (11) at the minimum compression point, where $\theta=$ 0 or $\pi$ (i.e. parallel to $\sigma_{H}$ ).

With geopressures, in-situ stresses, and the stress measured around the well, it is possible to determine, analytically, the maximum pump pressure based on the Mohr-Coulomb rupture criterion. These calculations seek to avoid the fracture of the reservoir by applying the equations previously presented and obtaining graphs that represent the stress conditions of the rock at initial conditions and on the perturbation submitted by the water injection, represented by the stress equations around the well. The quality and quantity of the measured data available will define the degree of reliability associated with each predicted parameter. In this case, the degree of reliability of the LOT data will translate the calibration quality of the data to be used and it will be used as a weighting factor for the analysis of errors of the proposed models and as a criterion for choosing the values of the calculated parameters. Thus, error analysis is an extremely important step in the study of data obtained through indirect methods.

The quantity and quality of the calibration data will define the degree of reliability associated with each property calculated. This degree of reliability will translate the calibration quality of the data to be used and it will be used as a weighting factor for the analysis of errors of the proposed models and as a criterion for choosing the values of the calculated parameters. Thus, error analysis is an extremely important step in the study of data obtained through indirect methods.

Relative Error (RE) is the error module at each point of the value measured by the direct methods 
compared to the value calculated by the indirect methods, defined as (Silva et al. 2018):

$R E(\%)=\frac{V M_{i}-V C_{i}}{V M_{i}} 100$

Where, $V M$ is the value measured by direct methods at depth $i$ and $V C$ is the value calculated by the indirect method at depth $i$.

The Average Relative Error (ARE) is the mean of the error of all measured points compared to the calculated values, defined as (Silva et al. 2018):

$\operatorname{ARE}(\%)=\frac{\sum_{i=1}^{N} \frac{V M_{i}-V C_{i}}{V M_{i}}}{N} 100$

Where, $N$ is the number of depth increments.

\section{RESULTS AND DISCUSSIONS}

By applying Equations (1), (2), and (3), the insitu stresses were initially determined as shown in Table 3. These results show the stress gradients (Figure 5) at the points that the LOT of $X$ and $Y$ wells were performed. Later, these values served as parameters for comparison and calibration of the calculated data using the geomechanical parameters obtained from Santos et al. (2015), Santos Jr (2015), and Silva et al. (2018), summarized in Table 4 . Note that the minimum
Table 3. In-situ stress for $X$ and $Y$ wells.

\begin{tabular}{lllllll}
\hline Depth & \multicolumn{2}{c}{$\sigma_{\text {ov }}$} & \multicolumn{2}{c}{$\sigma_{\mathrm{h}}$} & \multicolumn{2}{c}{$\sigma_{\mathrm{H}}$} \\
\hline $\mathbf{M}$ & $\mathrm{lb} / \mathrm{gal}$ & $\mathrm{MPa}$ & $\mathrm{lb} / \mathrm{gal}$ & $\mathrm{MPa}$ & $\mathrm{lb} / \mathrm{gal}$ & $\mathrm{MPa}$ \\
\hline 347 & 15.53 & 6.33 & 15.77 & 6.43 & 20.06 & 8.18 \\
487 & 16.67 & 9.54 & 16.56 & 9.47 & 21.33 & 12.20 \\
977 & 18.21 & 20.90 & 17.26 & 19.81 & 22.26 & 25.55 \\
997 & 18.25 & 21.38 & 17.11 & 20.04 & 21.79 & 25.52 \\
1,097 & 18.45 & 23.78 & 17.32 & 22.32 & 23.96 & 30.88 \\
1,485 & 18.88 & 32.94 & 17.18 & 29.97 & 24.51 & 42.76 \\
1,495 & 18.89 & 33.18 & 17.12 & 30.07 & 24.42 & 42.89 \\
2,235 & 19.44 & 51.05 & 16.93 & 44.46 & 25.97 & 68.19 \\
\hline
\end{tabular}

horizontal stress approaches the overburden pressure, and the maximum horizontal is greater than overburden, suggesting a strike-lip to reverse tectonic regime. According to Zang and Yin (2017) this occurs when formations are in tectonic stress regimes: two horizontal stresses can be equal to or even greater than the overburden stress. From Figure $4 a$, constant values $a$ and $b$, obtained from Equation 4, were equal to -0.135 and 1.825 , respectively.

As can be seen in Table 3, for the shallower depths of up to $977 \mathrm{~m}$, the values of horizontal stress are greater than vertical stress ones $(\sigma \mathrm{H}>$ $\sigma \mathrm{h}>\sigma o v)$, suggesting a regime of reverse fault (RFR). For the deeper sections, the fault current regime is the strike-slip or lateral (RFL) because the

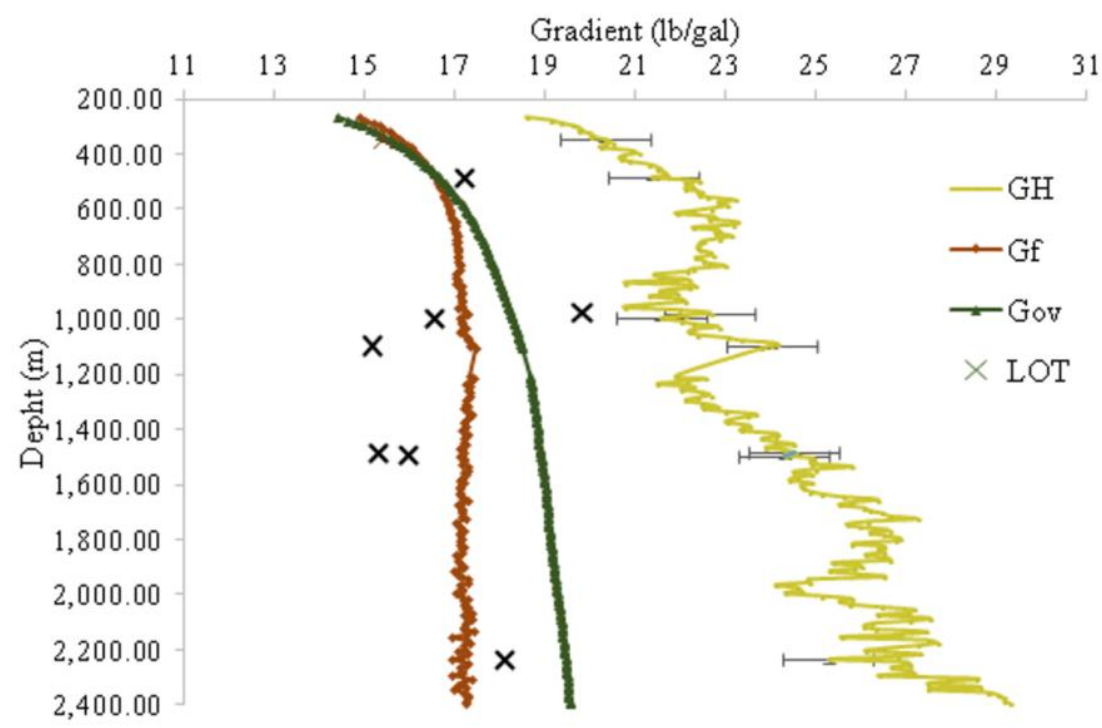

Figure 5. In-situ stress for $X$ and $Y$ wells. 
Table 4. Geomechanical parameters of the rock.

\begin{tabular}{llllllll}
\hline Depth (m) & Porosity (-) & $\mathbf{( v )}$ & $\boldsymbol{\varphi}(\mathrm{Rad})$ & $\boldsymbol{\mu}(\mathrm{MPa})$ & $\boldsymbol{2} \boldsymbol{\beta}(\mathrm{Rad})$ & UCS (MPa) & $\boldsymbol{S}_{\mathbf{0}}(\mathrm{MPa})$ \\
\hline 347 & 0.23 & 0.37 & 0.49 & 0.53 & 2.06 & 18.63 & 5.60 \\
487 & 0.20 & 0.34 & 0.49 & 0.54 & 2.07 & 21.58 & 6.42 \\
977 & 0.14 & 0.33 & 0.53 & 0.59 & 2.10 & 22.22 & 6.36 \\
997 & 0.16 & 0.29 & 0.53 & 0.59 & 2.10 & 22.76 & 6.50 \\
1,097 & 0.13 & 0.31 & 0.54 & 0.60 & 2.11 & 25.71 & 7.29 \\
1,485 & 0.09 & 0.29 & 0.56 & 0.63 & 2.14 & 27.58 & 7.58 \\
1,495 & 0.18 & 0.28 & 0.57 & 0.63 & 2,14 & 27.76 & 7.63 \\
2,235 & 0.10 & 0.24 & 0.61 & 0.70 & 2.18 & 31.01 & 8.04 \\
\hline
\end{tabular}

Table 5. Mohr-Coulomb Envelope.

\begin{tabular}{ccc}
\hline Depth $(\mathbf{m})$ & $\boldsymbol{\sigma}^{\prime}(\mathbf{M P a})$ & $\boldsymbol{\tau}(\mathbf{M P a})$ \\
\hline 347 & 3.36 & 7.38 \\
487 & 5.57 & 9.44 \\
977 & 10.55 & 12.56 \\
997 & 12.23 & 13.71 \\
1,097 & 12.53 & 14.78 \\
1,485 & 18.21 & 19.13 \\
1,495 & 18.83 & 19.58 \\
2,235 & 28.67 & 28.26 \\
\hline
\end{tabular}

values of the overburden stress are below the maximum horizontal stress $(\sigma \mathrm{H}>\sigma o v>\sigma h)$. The results corroborate with Lima Neto's work (Lima Neto, 1999) which explains that the tectonic regime of the Sergipe/Alagoas basin presents a predominance of compressive regime with reverse failures in the shallowest sections, becoming strikeslip in the deeper sections of the basin.

Finally, the use of the Mohr-Coulomb envelope was calculated, based on the geomechanical parameters of the rock presented in Table 4. Its values are presented in Table 5 and plotted in the

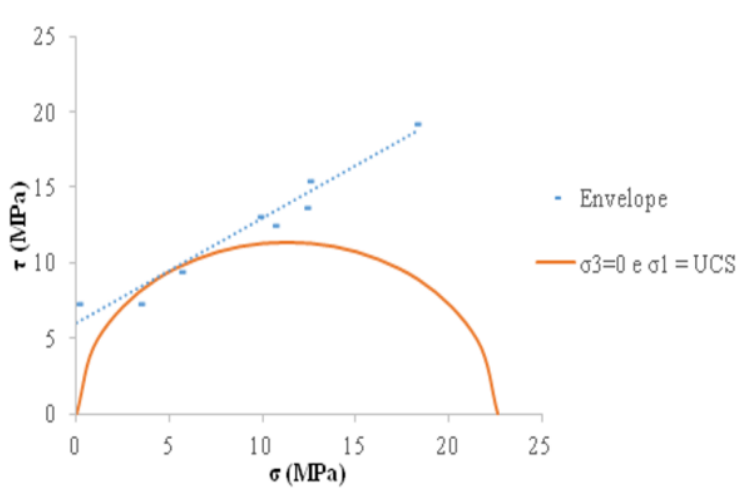

Figure 6. Mohr-Coulomb rupture envelope.

plane $\tau \times \sigma$ shown in Figure 6.

With the definition of the Mohr-Coulomb envelope, one can determine maximum pump pressures. Table 6 and Figures 7 and 8 present these values.

Maximum pumping pressure values presented in Table 6 were obtained by varying the pump pressure value until the Mohr circles reached a

Table 6. Maximum limit of pump pressure and stresses around the well defined by the Mohr-Coulomb rupture criterion.

\begin{tabular}{|c|c|c|c|c|c|c|}
\hline \multirow[t]{2}{*}{ Circles } & \multirow[t]{2}{*}{ Depth (m) } & \multicolumn{2}{|c|}{ Pumping Pressure } & \multirow[t]{2}{*}{$\sigma_{r}^{\prime}(\mathrm{MPa})$} & \multirow[t]{2}{*}{$\sigma_{a}^{\prime}(\mathrm{MPa})$} & \multirow[t]{2}{*}{$\sigma_{\theta}^{\prime}(\mathrm{MPa})$} \\
\hline & & lb/gal & $\mathrm{MPa}$ & & & \\
\hline 1 & 347 & 16.74 & 6.82 & 3.36 & 1.57 & 8.9E-05 \\
\hline 2 & 487 & 18.27 & 10.45 & 5.83 & 3.03 & 0.004 \\
\hline 3 & 977 & 18.22 & 20.91 & 10.23 & 6.43 & 0.007 \\
\hline 4 & 997 & 19.71 & 23.09 & 13.92 & 9.02 & 0.011 \\
\hline 5 & 1,097 & 16.78 & 21.63 & 9.74 & 6.48 & 0.006 \\
\hline 6 & 1,485 & 16.57 & 28.91 & 14.17 & 10.76 & 0.012 \\
\hline 7 & 1,495 & 16.83 & 29.56 & 15.34 & 11.71 & 0.003 \\
\hline 8 & 2,235 & 14.88 & 39.07 & 18.26 & 18.83 & 0.025 \\
\hline
\end{tabular}




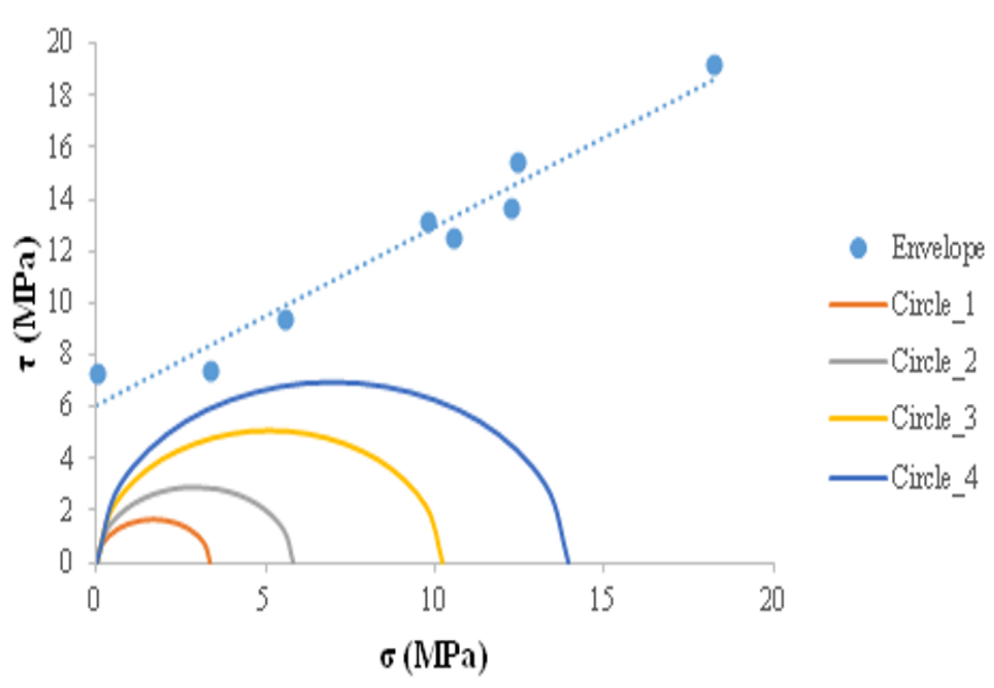

Figure 7. Mohr-Coulomb's rupture criterion for the plane $\tau \times \sigma_{n}$ for the first four LOT tests.

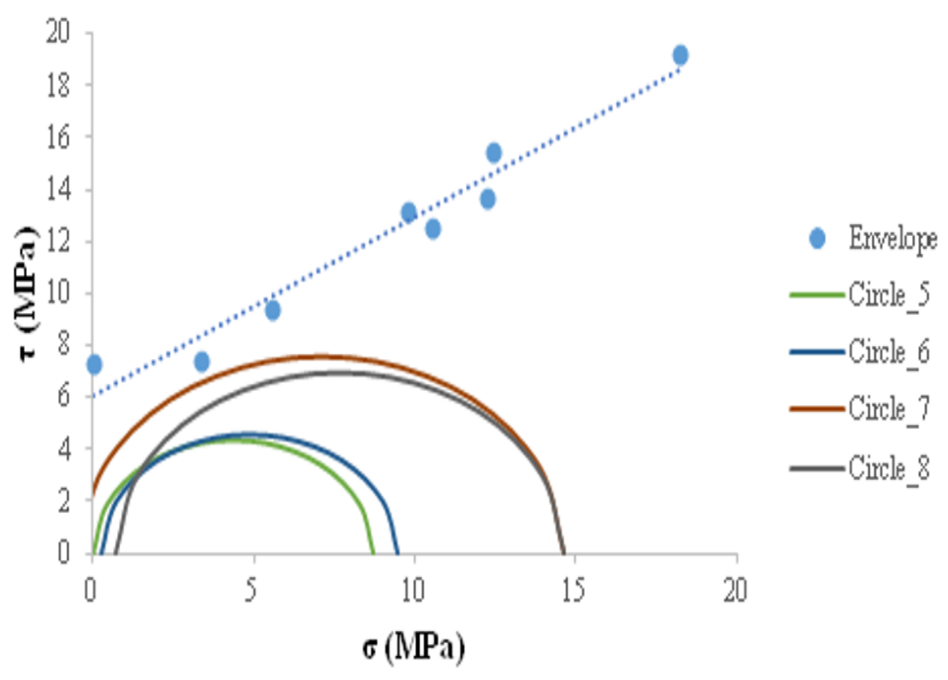

Figure 8. Mohr-Coulomb rupture criterion in the plane $\tau \times \sigma_{n}$ for the depths of the last four LOT tests.

state of traction $\left(\sigma_{3} \leq 0\right)$, thus, representing the limit of the stabilized state so that the rock fractures, as shown in Figures 7 and 8.

By performing the reliability analysis on the values of the maximum pumping pressure obtained by the Mohr-Coulomb rupture criterion and comparing them with the values obtained in the LOTs, one can verify that the calculated values overestimated the burst pressures presenting an average relative error of $7.87 \%$, showed in Table 7 , being an acceptable value within the petroleum industry, proving to be a usable tool for obtaining the fracture pressure of the rock.
Table 7. Reliability analysis of pump pressure values compared to the measured values of the absorption pressure (LOT).

\begin{tabular}{ccc}
\hline $\begin{array}{c}\text { LOT } \\
\text { (lb/gal) }\end{array}$ & $\begin{array}{c}\text { Mohr-Coulomb } \\
\text { (lb/gal) }\end{array}$ & $\begin{array}{c}\text { Relative Error } \\
\text { (\%) }\end{array}$ \\
\hline 15.40 & 16.74 & 8.70 \\
17.20 & 18.27 & 6.22 \\
19.80 & 18.22 & 7.98 \\
15.17 & 16.78 & 10.61 \\
15.30 & 16.57 & 8.30 \\
15.97 & 16.83 & 5.39 \\
\hline Average Relative Error (\%) & 7.87 \\
\hline
\end{tabular}


Table 7 shows that the use of the fracture pressure determined by the Mohr-Coulomb criterion is a conservative but realistic view that can be used by industry to predict the fracture gradient in injection projects. Mohr-Coulomb rupture criterion, with approach proposed by Zoback for determining horizontal stresses and using only well logging data, proved to be a reliable and cost-effective method to determine the rupture pressure of the rock. This method can be applied to other projects in the field under study or under similar conditions.

\section{CONCLUSIONS}

Through the diffused concepts of rock mechanics applied in the methodology of the present work, the values of the in-situ stresses, as well as the stresses around the well, can be measured using the data from two well logs located in the Sergipe/Alagoas - Brazil. This methodology makes it possible to measure the maximum pump pressure of the water injection method for the secondary oil recovery with the approach proposed by Zoback and the MohrCoulomb rupture criterion, using only well logging data. By means of quality control, it is possible to confirm the potential of the Mohr-Coulomb criterion that presented values of reliability about $7.87 \%$ of average relative error, allowing the determination of the maximum pump pressure of the water injection for the field under study, in a way that prevents the rupture of the cap rocks. The values obtained were validated with direct data obtained from measurements in local wells, as well as the stress regime obtained for the SergipeAlagoas basin, are agreement with other studies found in the literature. This study shows that the approach used is a practical, and it offers a lowcost tool that allows estimating the stress state around the well with a good estimate. Besides, it guarantees production within the safe conditions for the chosen recovery method, allowing the use of the methodology for other fields, with the purpose of refining and certifying the methodology applicability to the work.

\section{REFERENCES}

Almisned, A.O.; Al-Quraishi, A. A.; Al-Awad, M. $N$. Effect of triaxial in situ stresses and heterogeneities on absolute permeability of laminated rocks. Journal of Petroleum Exploration and Production Technology; v. 7, p. 311-316, 2017. https://doi.org/10.1007/s13202-016-0263-5

Aadnøy, B.; Looyeh, R. Mecânica de rochas aplicadas: perfuração e projeto de poços. Rio de Janeiro: Elsevier; 2014.

Anderson, R. A.; Ingram, D. S.; Zanier, A. M. Determining fracture pressure gradients from well logs. Journal of Petroleum Technology, v. 25, p. 1259-1268, 1973. https://doi.org/10.2118/4135-PA

Amadi, A. O.; Onwukwe, S. I.; Udie, C. A. Analysis of water injection in an artificially fractured reservoir. American Journal of Engineering Research., v. 6(5), p. 287-300, 2017.

Azevedo, M. S. Análise geomecânica aplicada à análise de estabilidade de poços. Projeto de Graduação, Curso de Engenharia de Petróleo, Escola Politécnica, Universidade Federal do Rio de Janeiro; 2011 (in Portuguese).

Cao, G. S.; Tan, C.; Song, F. C.; Qin, Z. C.; Yang, $W$. W. Pressure limit of enhanced water injection in low-permeability oilfield. Science Technology and Engineering, v. 12(13), p. 3107-3111, 2012.

Daines, S. R. Prediction of fracture pressures for wildcat wells. Journal of Petroleum Technology, v. 34, p. 863-872, 1982. https://doi.org/10.2118/9254PA

Doyle, E. F.; Berry, J. R.; Mocormack, N. J. Plan for surprises: pore pressure challenges during the drilling of a deep water exploration well in midwinter in Norway. Society of Petroleum Engineers, SPE/IADC Drilling Conference,19-21 February, Amsterdam, Netherlands, 2003.

https://doi.org/10.2118/79848-MS

Eaton, B. A. Fracture gradient prediction and its application in oilfield operations. Journal of Petroleum Technology, v. 21(10), p. 1353-1360, 1969. https://doi.org/10.2118/2163-PA 
Fjaer, E.; Holt, R. M.; Horsrud, P.; Raaen, A. M.; Risnes, R. Petroleum Related Rock Mechanics. V. 53, $2^{\text {nd }}$ Edition, Amsterdam: Elseveir, 2008.

Hackston, A.; Rutter, E. The Mohr-Coulomb criterion for intact rock strength and friction - a reevaluation and consideration of failure under polyaxial stresses. Solid Earth, v. 7, p. 493-508, 2016. https://doi.org/10.5194/se-7-493-2016

Holbrook, P. W.; Maggiori, D. A.; Hensley, R. Real-time pore pressure and fracture gradient evaluation in all sedimentary lithologies. Society of Petroleum Engineers, SPE Formation Evaluation, v.10(4), SPE-26791-PA, 1993.

Hussain, M.; Ahmed, N. Reservoir Geomechanics parameters estimation using well logs and seismic reflection data: insight from Sinjhoro Field, Lower Indus Basin, Pakistan. Arabian Journal for Science and Engineering, v. 43, p. 3699-3715, 2018. https://doi.org/10.1007/s13369017-3029-6

Hussein, A. M.; Heiland, J. 3D finite element modelling of multilateral junction wellbore stability. Petroleum Science, v. 15, p. 801-814, 2018. https://doi.org/10.1007/s12182-018-0251-0

Jesus, F. A.; Silva, J. V.; Batista, A. I. S.; Andrade, L. R. S.; Oliveira, M. J.; Borba, C. Determinação das propriedades mecânicas das rochas a partir da perfilagem de poços em reservatórios tight sands. Scientia Plena, v. 15, p. 1-15, 2019. (In Portuguese) https://doi.org/10.14808/sci.plena.2019.015301

Lal, M. Shale Stability: Drilling Fluid Interaction and Shale Strength. Society of Petroleum Engineers, SPE Asia Pacific Oil and Gas Conference and Exhibition,20-22 April, Jakarta, Indonesia, SPE54356-MS. 1999. https://doi.org/10.2118/54356-MS

Lima Neto, F. F. Regime atual de tensões nas bacias sedimentares brasileiras. VII Simpósio Nacional de Estudos Tectônicos, May $12^{\text {th }}-15^{\text {th }}$, p. 25-28, Lençois, Bahia, Brazil, 1999. (In Portuguese)

Lyu, W.; Zeng, L.; Chen, M.; Qiao, D.; Fan, J.; Xia, D. An approach for determining the water injection pressure of low-permeability reservoirs. Energy Exploration \& Exploitation, v. 36(5), p. 1210-1228, 2018. https://doi.org/10.1177/0144598718754374
Manshad, A. K.; Jalalifar, H.; Aslannejad, M. Analysis of vertical, horizontal, and deviated wellbores stability by analytical and numerical methods. Journal of Petroleum Exploration and Production Technology, v. 4, p. 359-369, 2014. https://doi.org/10.1007/s13202-014-0100-7

McPherson, L. A.; Berry, L. N. Prediction of fracture gradients from log-derived elastic moduli. Society of Petrophysicists and Well-Log Analysts, v.13(5), p.12-19, 1972.

Molaghab, A.; Taherynia, M. H.; Aghda, S. M. F.; Fahimifar, A. Determination of minimum and maximum stress profiles using wellbore failure evidences: a case study-a deep oil well in the southwest of Iran. Journal of Petroleum Exploration and Production Technology, v. 7, p. 707-715, 2017. https://doi.org/10.1007/s13202-0170323-5

Mollakhorshidi, A.; Arabjamaloei, R. The estimation of a formation fracture pressure gradient by using drilling data and artificial neural networks. Energy Sources Part A. v. 34(15), p. 1384-1390, 2012. https://doi.org/10.1080/15567036.2011.574191

Matthews, W. R.; Kelly, J. How to predict formation pressure and fracture gradient from electric and sonic logs. Oil \& Gas Journal, v. 65, p. 96-106, 1967.

Pennebaker, E. S. An engineering interpretation of seismic data. Society of Petroleum Engineers, Fall Meeting of the Society of Petroleum Engineers of AIME, SPE-2165-MS, 29 September-2 October, Houston, Texas 1968.

https://doi.org/10.2118/2165-MS

Postler, D. P. Pressure integrity test interpretation. Society of Petroleum Engineers, SPE/IADC Drilling Conference, SPE-37589-MS, 4-6 March, Amsterdam, Netherlands, 1997.

https://doi.org/10.2118/37589-MS

Rocha, L. A. S.; De Azevedo, C. T. Projetos de poços de petróleo: Geopressões e assentamento de colunas de revestimentos. Rio de Janeiro: Interciência, 2008.

Rosa, A. J.; Carvalho, R. S.; Xavier, J. A. D. Engenharia de Reservatórios de Petróleo. Rio de Janeiro: Interciência, 2011. 
Rutqvist, J.; Birkholzer, J. T.; Cappa, F.; Tsang, C. F. Estimating maximum sustainable injection pressure during geological sequestration of $\mathrm{CO}_{2}$ using coupled fluid geomechanical fault-slip analysis. Energy Conversion and Management, v. 48, p. 1798-1807, 2007.

https://doi.org/10.1016/i.enconman.2007.01.021

Santos, J. P. L.; Andrade, J. F.; Oliveira, R. C.; Almeida Neto, J. B.; Santos, A. P. P. Projetos de poços: um estudo de caso na bacia SergipeAlagoas. Revista Eletrônica de Petróleo e Gás, v. 3, p. 31-40, 2015.

Santos, D. F.; Santos, D.; Souza, W. J. Development of a gui interface for geopressure detection during well drilling. Brazilian Journal of Petroleum and Gas, v. 12(1), p. 53-60, 2018. https://doi.org/10.5419/bjpg2018-0005

Santos Jr, E. X. Ajuste da curva de k para a determinação do gradiente de fratura em projetos de poços na bacia Sergipe-Alagoas. Dissertação, Universidade Federal de Sergipe, 2015. (in Portuguese).
Silva, M. N.; Santos, J. P. L.; Oliveira, R. C.; Souza, I. S.; Cunha, A. L. Avaliação da aplicação dos métodos indiretos de predição do gradiente de pressão de poros em projetos de poços da Bacia Sergipe-Alagoas. Revista Geologia USP. Série Científica, v. 18(2), p. 19-28, 2018. (in Portuguese) https://doi.org/10.11606/issn.2316-9095.v18-125669

Zang, J.; Yin, S. X. Fracture gradient prediction: an overview and an improved method. Petroleum Science, v. 14, p. 720-730, 2017. https://doi.org/10.1007/s12182-017-0182-1

Zoback, M. D. Reservoir Geomechanics. Cambridge University Press: Cambridge, 2007. https://doi.org/10.1017/CBO9780511586477 